\title{
Population, The Labor Force, and Potential Output: Implications for the St. Louis Model
}

\author{
by ROGER W. SPENCER
}

\section{3.} OPULATION, the labor force and output have been increasing in this country for the past two hundred years. The simple observation that population growth leads to increases in the labor force and, consequently, to employment and output gains, holds quite well over the long run, but the relationships are considerably more complex over shorter periods. The current interest in population growth, and the present uncertainties surrounding the expected future course of employment and overall economic activity, encourm age this investigation into the relevant short-term relations.

This article discusses first the chief determinants of population growth. Labor force considerations and employment are then introduced. Next, output and potential output concepts are considered. Finally, all of these factors are combined in a projection of the future course of prices, unemployment and real output, using the model of the economy developed at this Bank. The results of the projection indicate that varying rates of growth of the forces which determine the potential supply of goods and services have different implications for the future course of prices, unemployment, and real output.

\section{Population}

Population growth in a country is detemined by the birth rate, the death rate, and the net immigration rate. Usually, these rates are expressed in ratio form. For example, the birth rate is the number of births during a year divided by the midyear poptation. Multiplying this figure by 1000 gives the number of births per 1000 people.

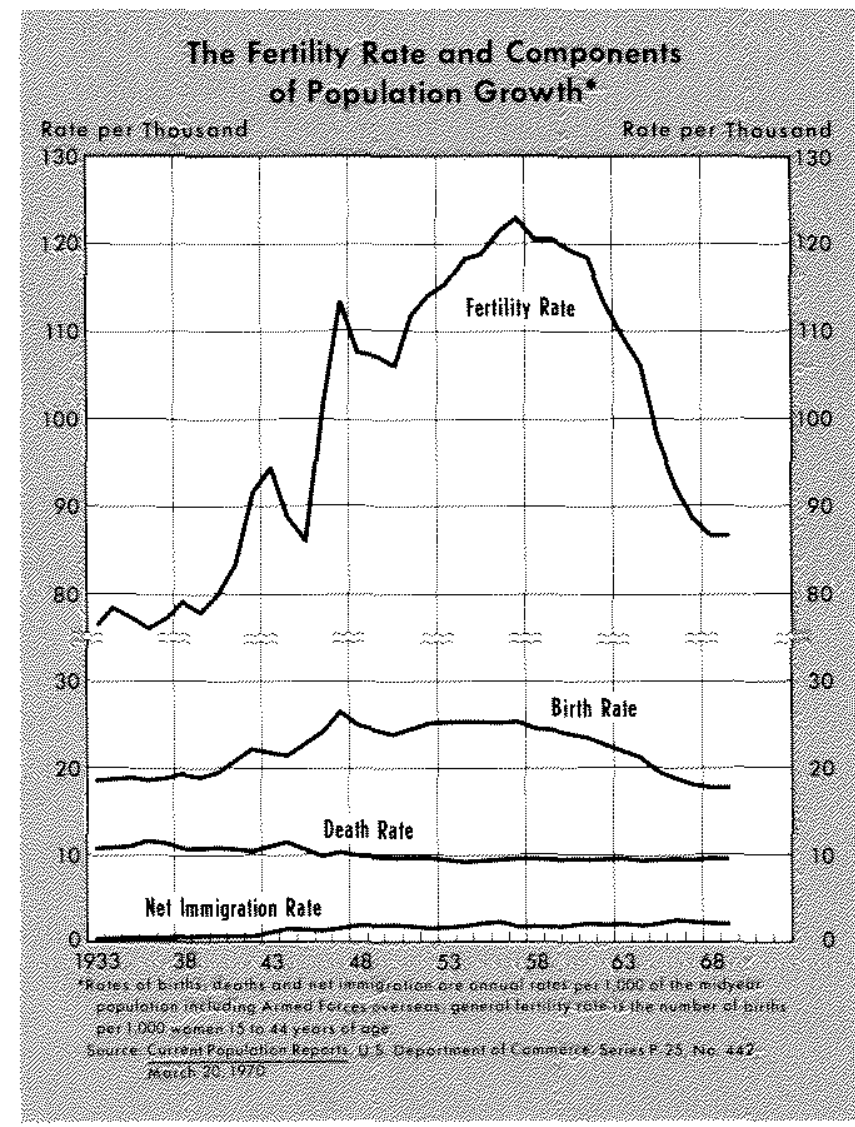

The death rate in this country has stabilized at about 9.5 deaths per 1000 people annually since World War II, and the net immigration rate has stabilized at about 2 per 1000 people, making the birth rate the key determinant of population growth. The "crude" birth rate, or the number of births per 1000 people, should be supplemented in population analysis by examina- 
tion of more sophisticated birth measures, such as the general fertility rate (see accompanying chart). This is an "age-specific" rate, ${ }^{1}$ and is usually calculated as the ratio of births to all women $15-44$ years old divided by the midyear female population in this age group (with the ratio mutiplied by 1000 ).

Fertility rates are highest among women $20-29$ years of age. An analysis of the number of women in this age group and their corresponding fertility rate is a key element in the ability to forecast population growth. This fertility rate is largely dependent upon attitudes toward marriage, birth control and family size, and employment. The difficulties in attempting to gauge these changing attitudes are reflected by the Census Bureau's projection of several widely differing, alternative fertility rates into the 21st century.

Current birth or fertility rates are of major significance in the analysis of current population trends and, with at least a 16-year lag, trends in population of labor force age. Current births add to the total demand for goods and services, but their impact on total supply is not felt for a minimum of 16 years.

\section{The Labor Force}

The population of labor force age, often defined to include all persons 16-64 years of age, is known with considerable certainty nearly two decades into the future. Knowledge of the population of labor force age and the proportion of this population which actively participates in the labor force provides a basis for projecting the size of the total labor force.

Certain groups of persons within the population of labor force age can be expected to seek employment as a matter of course. The evidence suggests that males between the ages of 25 and 54 (primary workers) participate actively in the labor force, in that nearly all who are employable either hold a job or are seeking one. Other groups (often called secondary workers) within the population of labor force age are not so likely to be regularly interested in employment.

The reasons underlying the decisions of secondary workers to seek or not to seek employment vary considerably. ${ }^{2}$ Many are only a little less likely to par-

\footnotetext{
An age-specific rate is employed for a particular subgroup of the population. A specific rate applied to a gender, for example female, combined with a particular age group, for example 20-29 years, gives an age-specific rate for females aged 20-20. See Donald J. Bogue, Principles of Demography (New York: John Wiley and Sons, Inc., 1969), p. 119.

${ }^{2} \mathrm{~A}$ large body of literature on participation rates has emerged in recent years. See, for example, William Bowen and $T$.
}

ticipate in the labor force than primary workers, but others, such as students and housewives, require additional motivation. In general, desired hours of work, particularly for secondary workers, are based on leisure-wage considerations. A rise in the wage rate (which is often accompanied by improved working conditions and shorter job search time) may encourage an individual to work fewer hours and maintain the same level of income, or substitute work for leisure because each hour of leisure becomes more expensive in terms of foregone income. Falling wage rates, which would probably be accompanied by falling income levels and longer job search time, may stimulate some potential workers to seek at least part-time employment in order to supplement the lower basic family income. These additional entrants to the labor force may be offset, however, by workers who become discouraged by the low demand for their services and withdraw from the labor force. Most studies indicate that the "discouraged worker" effect (the substitution of leisure for work) is generally stronger than the "additional worker" (or income) effect. ${ }^{3}$

The trend of participation rates has shifted in recent years. The participation rate of women, for example, has increased strikingly in the past two decades. Their participation rate rose from 34 per cent in 1950 to nearly 43 per cent in 1969 . Changing attitudes toward family size and the role of women in society have contributed to an increased supply of female labor. Other factors include shifts from physical and manual labor to lighter work in factories, and the growth of white collar jobs in government and business, especially service-oriented industries.

\section{Output}

The number of workers of labor force age, and the rate at which this volume of potential labor resources

Aldrich Finegan, The Economics of Labor Force Participafion (Princeton, New Jersey: Princeton University Press, 1969 ); N. J. Simler and Alfred Tella, "Labor Reserves and the Phillips Curve," The Review of Economics and Statistics, February 1968; V. Perella, "Women and the Labor Force," Monthly Labor Review, February 1969; Jacob Mincer, "Labor Force Participation and Unemployment: A Review of Recent Evidence," in Prosperity and Unemployment, edited by Robert A. Gordon and Margaret S. Gordon (New York: John Wiley and Sons, Ine., 1966); and A. Butler and $G$. Demoponlos, "Changing Patterns of Labor Force Participation," a paper presented at the National Economic Conference, Thessaloniki, Greece, March 1970 .

${ }^{3}$ "Studies of the United States economy, covering the period from the end of World War II up through the early $1960^{\circ} \mathrm{s}$, are unanimous in finding the 'discouraged" worker effect predominating over the "additional' worker effect." See Butler and Demopoulos, p. 8 . 
actively participates in the work force, are major determinants of the level of employment. The level of employment is a key deteminant of the volume of labor input (man-hours worked) in the economy. Man-hours worked, and the degree of efficiency with which they are combined with other productive factors, determine the volume of output.

A constant level of employment does not necessarily suggest a constant number of man hours worked. Overtime, moonlighting, a reluctance to release employees at the beginning of a recession, and a trend toward more leisure hours, all tend to influence the linkages between employment and labor input,

Rising efficiency in the combination of labor and other productive factors generates productivity gains. Advances in technology and education are largely responsible for the rising trend of output relative to factor inputs. In the short run, however, output rela tive to input may vary in response to changing business conditions. For example, a cyclical downtum is often marked initially by a fall in output which develops before the downward adjustment of employment growth.

If cyclical influences are ignored, it is possible to estimate the level of output which can be generated by an economy operating at full employment, that is, potential output. The best-known measure of potential output is that which is calculated by the President's Council of Economic Advisers (CEA). Assumptions regarding the labor force, employment, and productivity must be made in order to derive this measure of potential ontput.

The CEA bases its estimate of the growth of real potential output on assumed rates of change of the civilian labor force and the average hours of work per person (to obtain estimates of labor input) and the assumed growth in productivity (to indicate the degree of efficiency with which labor is combined with other productive factors). The CEA projections of real potential output from 1970 to 1975 assume that a state of full employment exists when 96.2 per cent of the labor force is employed." The increasing desire for leisure is reflected in a projection of further declines in the annual average hours of work per person. Productivity estimates allow for the fact that a rising government sector (in which productivity is defined to be equal to zero) reduces overall productivity growth.

\footnotetext{
See The Economic Report of the President (Washington: United States Government Printing Office, 1970), pp. 84-5 Earlie: editions of the Economic Report indicate an assurned level of full employment of 96 per cent of the labor force.
}

Estimates employing these assumptions yield a relatively constant trend line of real potential output. For example, real potential output is estimated by the CEA to rise at a 4.3 per cent annual rate in each quarter from the fourth quarter of 1971 to the fourth quarter of 1975.5

\section{The Interaction of the Labor Force, Productivity and Other Economic Variables}

The interaction of the labor force, productivity, and other variables to form potential output is illustrated in Exhibit I. The diagram is a simplified representation of a possible method of determining potential output. " Several altemative methods are currently available (see footnote 5 ). The diagram indicates that population, social and economic (demand) factors are the prime determinants of labor input. Economic, technological and educational factors must be considered in the determination of productivity. ${ }^{\top}$ Industry mix is also of importance. For example, a large in"An alternative estimate of the growth of potential output has
been calculated by Ray Fair. His estimates allow explicitly
for the fact that labor hours worked differ from labor hours
paid for, and for the often rapidly changing 10 ow of man-
power between military and civilian employment. As a re-
sult, his estimates of potential output (calculated at a 96 per
cent level of employment) vary from quarter-to-quarter. See
Ray Fair, "Aggregate Price Changes and Price Expectations,"
this Review (November 1970 ), and "The Determination of
Aggregate Price Changes," mimeographed, Princeton Univer-
sity, June 1969 .

For other methods of estimating potential output, see Stanley Black and Robert Russell, "An Alternative Estimate of Potential GNP," Review of Economics and Statistics, Fobruary 1969 , pp. 70-6; Arthur Okun, "Potential GNP: Its Measurement and Significance," Proceedings of the Btsiness and Economic Statistics Section of the American Statistical Association, 1962; and Lester Thurow and L. D. Taylor, "The Interaction Between the Actual and the Potential Rates of Growth" Review of Economics and Statistics (November 1966), pp. 351-60. Black and Russell utilize regression analysis in combining their estimates of potential labor force and hours of work with a "Cobb-Douglas" production function. Their production function, which is characterized by a constant rate of disembodied technical progress, provides the necessary inputoutput relation. Okun's estimates of potential output, derived from a simplistic "law" which relates output and employment, are marked by quarter-to-quarter variances. Thurow and Taylor calculate several potential rates of growth under different assumptions about embodied and disembodied technical progress. A primary difference between their approach and that of Black and Russell is Thurow and Taylor's employment of a Solow production function instead of the more basic Cobb-Douglas production function.

one simplification found in Exhibit $I$ is the full employment adiustment made after the determination of labor input and measured productivity. This adjustment is generally made at earlier stages than shown in this diagram.

Troductivity, or measured productivity as it is labeled in Exhibit I, roughly corresponds to an average productivity of labor function in which $\mathrm{AP}_{\mathrm{L}}=\mathrm{Q} / \mathrm{L}: \mathrm{AP}_{\mathrm{L}}$ = average productivity of labor, $Q=$ aggregate level of output, and $L=$ aggregate level of labor inputs. See M. Ishaq Nadiri, "Some Approaches to the Theory and Measurement of Total Factor Productivity: A Survey," Joumal of Economic Literature, December 1970 , p. 1138 


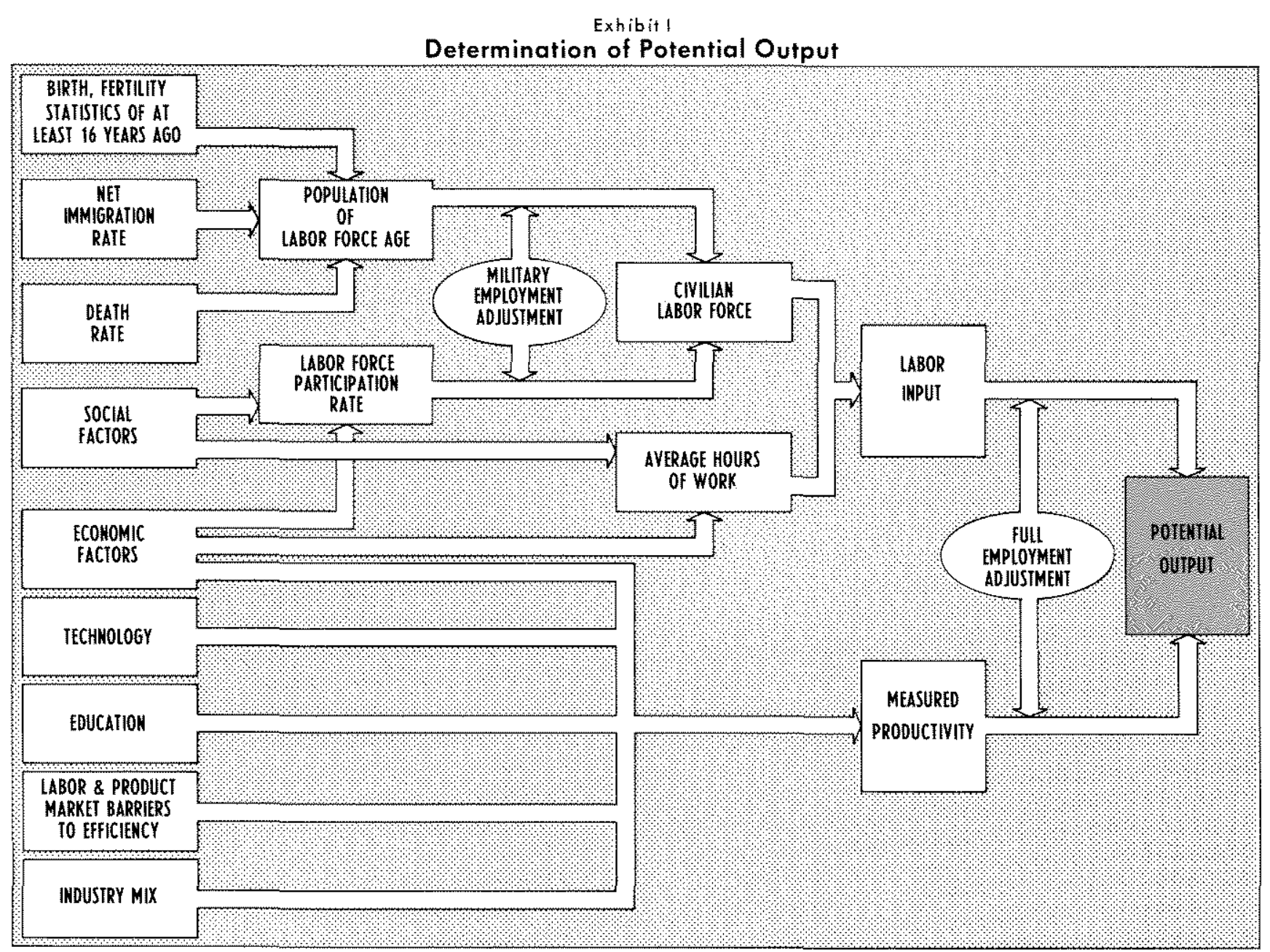

crease in the size of the government sector (a sector in which productivity is defined to be equal to zero) relative to other sectors of the economy would tend to reduce overall productivity, other things equal. Sizable shifts toward service industries, in which productivity is relatively low, would also tend to diminish total productivity. Productivity is lessened by labor and product market barriers to efficiency. Efficiency, in most instances, is enhanced by permitting the free play of competitive forces.

Potential output is comprised of those productive factors which supply goods and services to an economy. An accurate estimate of the potential supply of goods and services relative to the demand should provide some information on the outlook for real output, employment, and prices. Since potential output is influenced by the size of the labor force, among other things, and the labor force is dependent upon the population of labor force age (and the participation rate), one step in analyzing potential output growth is to examine population statistics of at least 16 years ago.

The rapid rise in the fertility and birth rates in the 1946 to 1957 period accounts for the large increase in the population of labor force age throughout most of the 1960 's. Teenagers and women entered the labor force in large numbers in the 1960's. Teenagers accounted for 7.3 per cent of the labor force in 1960 and 8.8 per cent in 1969. Women constituted 32.3 per cent of the labor force in 1960 and 36.3 per cent in 1969 . Assuming an unchanged participation rate, teenagers should continue to enter the labor force at rapid rates until the mid-1970's. After that, the generally declining birth rate since 1957 will tend to slow the volume of teenage entrants, while the proportion of workers in the labor force (both men and women) in their late 20 's and early 30 's will rise. The population of working force age should rise at about a 1.7 per cent rate from 1970 to 1975 and slow to a 1.5 per cent rate from 1975 to 1980 (see Table I). 


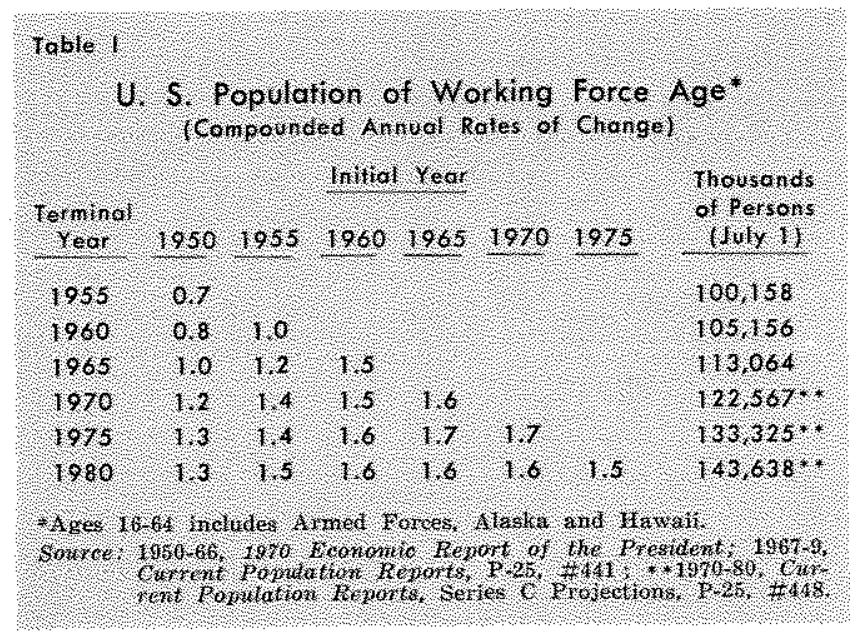

Projecting the labor force participation rate is a much more difficult task than gauging the population of labor force age. Each sex-age group is influenced differently by numerous economic and social factors. The Bureau of Labor Statistics anticipates that 94 per cent of the growth in the labor force throughout the 1970 's will be due to a rising population of labor force age, and the remaining 6 per cent will be attributable to expected increases in the participation rate. ${ }^{8}$

Determination of potential output requires modify ing total labor force estimates by subtracting military personnel in order to obtain the size of the civilian labor force. Currently, it appears that military employment will continue to slacken in response to the scheduled withdrawal from Vietnam. Release of manpower from military duty tends to expand the size of the civilian labor force, increase the volume of labor input and, therefore, potential output. Longer-run projections of military requirements generally assume a return of Armed Forces strength to pre-Vietnam escalation levels. ${ }^{9}$

The size of the civilian labor force adjusted for average hours of work provides a measure of the volume of labor input. Average hours of work paid for have been declining for several years and are expected to continue to fall slowly. ${ }^{10}$ The chief reasons for the decline are an apparent rise in the desire for leisure and the increasing proportion of part-time workers, associated, in large measure, with the rising significance of the service sector in the American economy.

\footnotetext{
8See "The U. S. Economy in 1980," Monthly Labor Review, April 1970, p. 6.

9Ibid., p. 4.

10lbid, pp. 6-7.
}

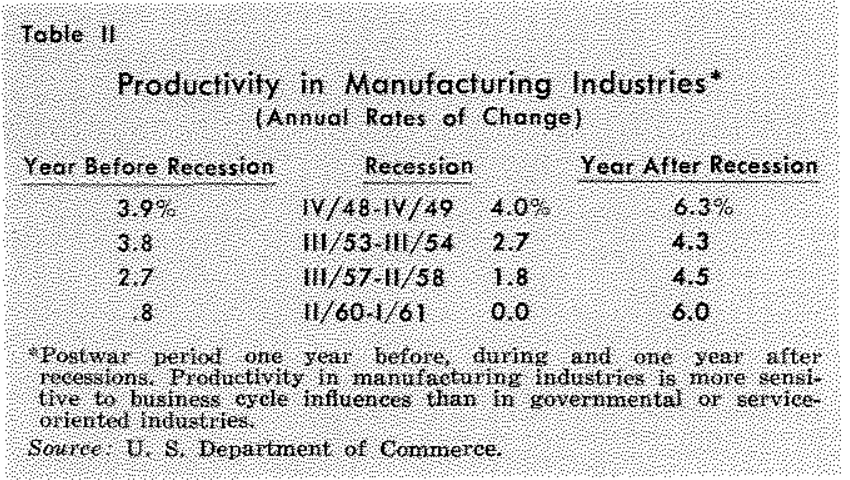

Productivity gains, which in the long rum depend largely on advances in technology and education, vary over shorter periods with industry and business cycle shifts. Total productivity has risen at a 3.1 per cent annual rate in the post World War II period, but a definite cyclical pattern has emerged, probably reflecting the lagged response of input to output changes (see Table II). Productivity growth is expected to slacken somewhat to an annual rate of 3 per cent or slightly less in the $1970^{2} \mathrm{~s}^{11}$

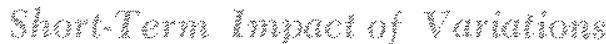

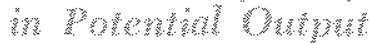

One technique for analyzing the effect of varying rates of growth of labor inputs and productivity is to examine the role played by potential output in this Bank's model of the economy. Potential output enters the model to reflect the economy's supply capacity (see Exhibit II). ${ }^{12}$ Total demand for goods and services, which is determined by monetary and fiscal actions, interacts with a supply capacity variable to determine demand pressure on the price level. The further the economy is from producing goods and services at a full employment level of output, the less the demand pressure on prices and the more the "spillover of demand" into real output. The closer the economy is to supplying the full-employment level of output, the more total demand is reflected in rising prices and the less is manifested in greater real output.

The model combines the demand pressure variable with an estimate of anticipated prices to obtain the current price level. Real output is obtained by eliminating the effects of price changes from nominal GNP. A fourth endogenous variable, the unemployment rate, can be derived as shown in Exhibit II.

\footnotetext{
11Ibid., p. 3, and Economic Report of the President, 1970, p. 84.

12The potential output relation actually employed in the model is the difference between current potential output and last quarter's real output $\left(X_{t}^{1}-X_{t-1}\right)$.
} 


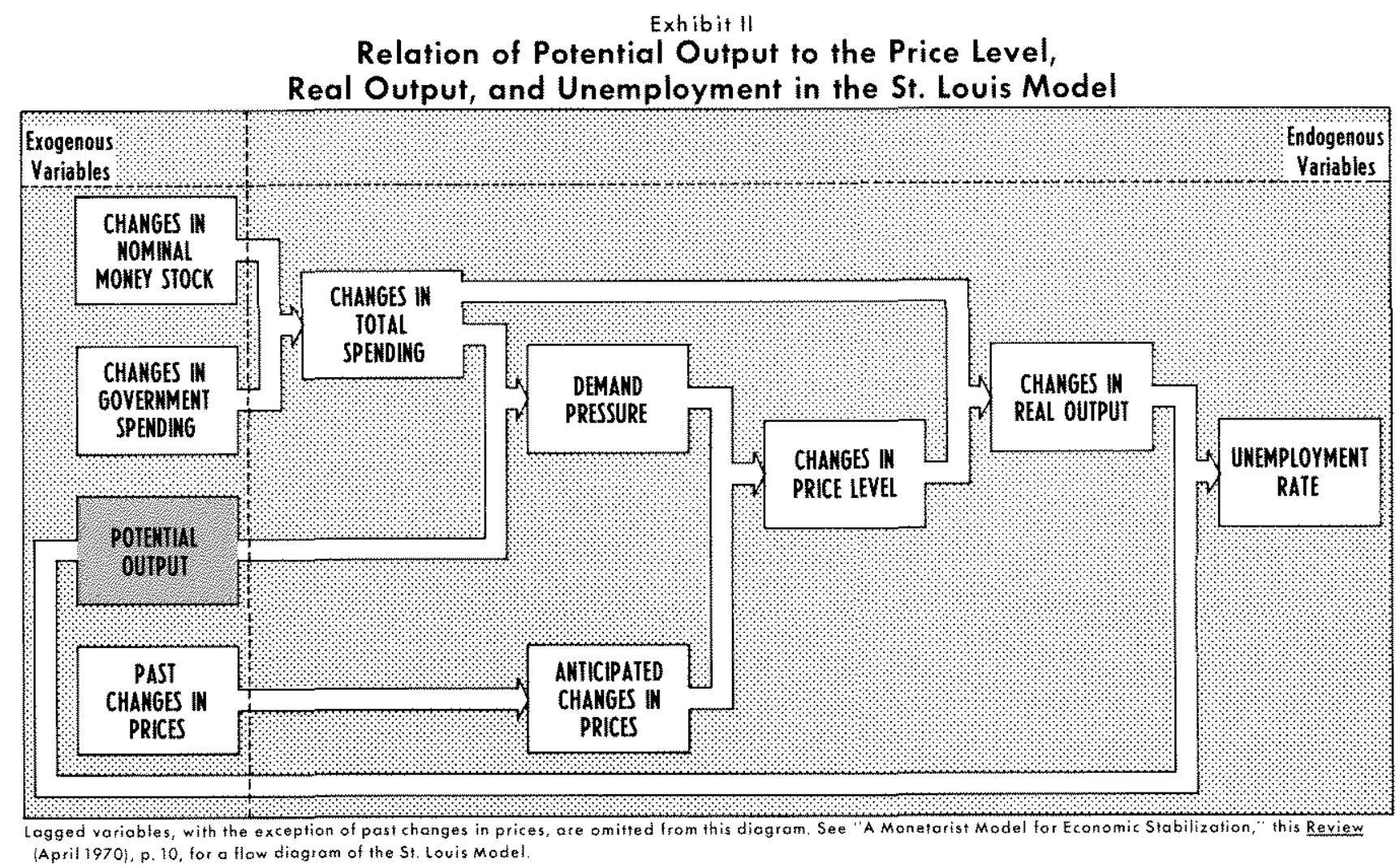

Potential output is the only exogenous variable which has not been analyzed in some detail in earlier discussions of the model in this Review. The model currently employs the trend-dominated CEA estimates of potential output. Because of short-run variations in labor input and productivity, however, realistic estimates might allow for quarterly potential output changes. ${ }^{ \pm 3}$

Projections of the model's endogenous variables over the relatively short period of two years may reflect some impact of the varying estimates of potential output. In order to gauge this impact, the model was simulated over the I/1971-IV/1972 period with potential output calculated to grow at a relatively slow rate of 2.5 per cent and a relatively rapid rate of 5.5 per cent annually (see Table III). It is possible to conjecture circumstances which would lead to very slow or very rapid increases in potential output over the next two years. These cireumstances depend primarily on

\footnotetext{
13The estimates of potential output made by Ray Fair, "Aggregate Price Changes and Price Expectations," in gauging quarterly changes since 1954 , reflect a 4.5 per cent average rise in potential output from nid-1962 to mid-1963 and a 2.5 per cent average increase from mid-1965 to mid-1966 (the Vietram troop escalation). At no time from 1955 to

1975 (estimated) have the CFA estimates been less than 3.5 per cent nor more than 4.4 per cent.
}

shifts in labor input, since those factors influencing full employment productivity are primarily of a longrun nature.

Labor input could fall because of a downward shift in the civilian labor force, the participation rate, or average hours worked. For example, a sizable shift away from the practice of birth control could lead to a withdrawal of women from the labor force. If the Vietnam effort is not de-escalated as anticipated, or if some new military conflict arises, the civilian labor force would not grow as rapidly as otherwise. Productivity could be restrained if $1971-72$ economic activity is dominated by economic sectors not employing efficient production techniques. The use of older machinery, failure to replace deteriorating plant or equipment or failure to embark on new investment projects, could lessen capital/labor productive efficiency.

A more optimistic outlook for potential output could be achieved by reversal of the factors outlined above. For example, if military personnel are retumed from Vietnam and channeled into the civilian labor force as fast as they were withdrawn in 1965-66, labor inputs would rise rapidly. Improvements in labor mobility and skills and the elimination of product and labor 
market monopolies might increase both labor inputs and productive efficiency.

Employing the slow $(2.5 \%)$ and rapid $(5.5 \%)$ potential output alternatives in the model of this Bank gives the results summarized in Table III. The money supply is assumed to grow at a 5 per cent rate throughout the two-year period; high-employment Government expenditures are estimated to second quarter 1972, and projected to grow at an 8 per cent annual rate thereafter.

Since the growth rate of nominal GNP is determined in the St. Louis model solely by a constant term and monetary and fiscal actions, changes in the growth rate of potential output cannot influence total spending. The division of nominal GNP into its components, real GNP and the price level, is strongly influenced by the rapid or slow growth of potential output. The postulated relation between real and potential output also proves to have considerable significance for the unemployment rate.

Slow growth of potential output at a 2.5 per cent rate has the effect of restraining the rate of real GNP growth. Even the slow rise of real GNP is large relative to potential output growth, however, thus stimulating continued price increases through the demand pressure variable. Anticipations of continued inflation, based on past changes in prices (see Exhibit II), also tend to retard progress in halting price rises. By the end of 1972, real output is projected to increase at a 2.7 per cent annual rate while prices rise at a 3.8 per cent rate. The poor progress in combatting inflation is

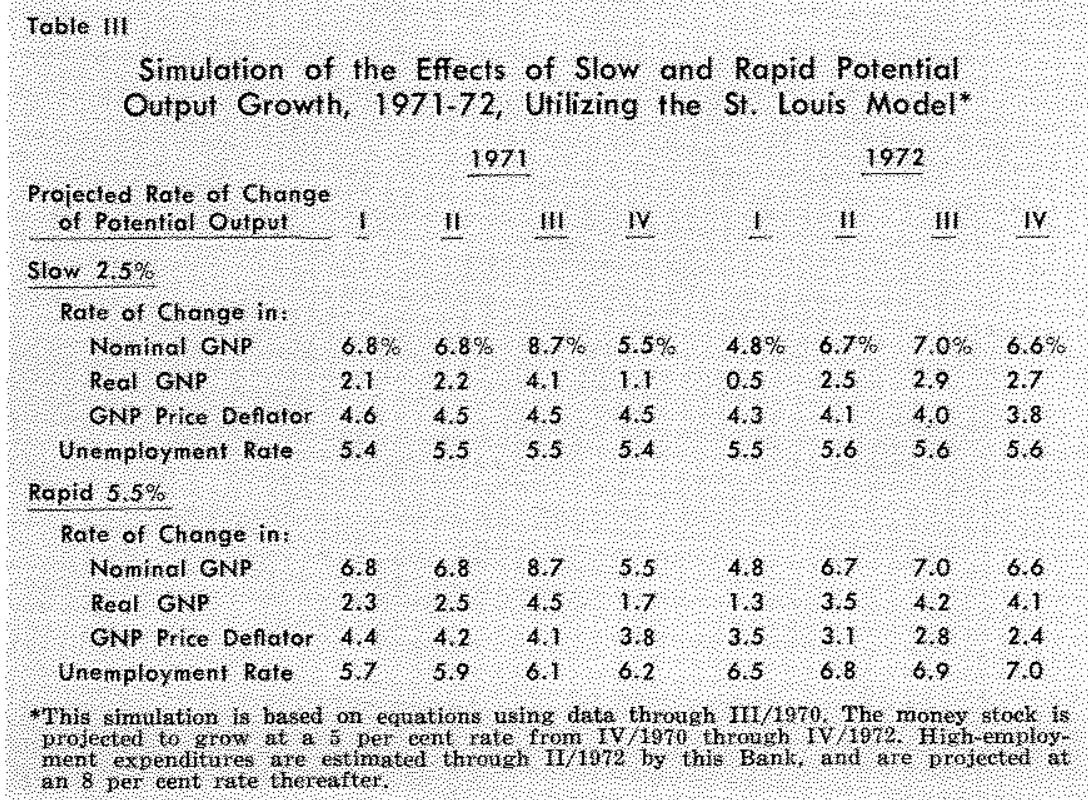

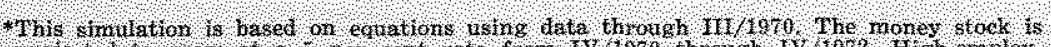
0.03 eted 60 s

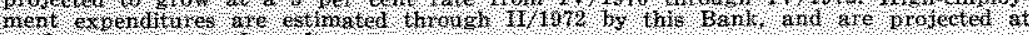
an 8 en eent tute ontretert

"traded-off" over this two-year period against a 5.6 per cent rate of unemployment at the end of 1972.

The discouraging feature implied by a 5.5 per cent rate of growth of potential output is the rise of the unemployment rate to 7 per cent at the end of the two-year period. A rapid infusion of Vietnam war veterans into the civilian labor force is consistent with this projection. By way of contrast with the projection of potential output at a slow rate, a 5.5 per cent rate of increase in potential output implies that prices will slow to a 2.4 per cent rate, and the rate of increase of real output will rise to 4.1 per cent by the end of 1972 .

The economic conditions existing at the beginning of the simulation period are particularly important with regard to the movements of the endogenous variables under either potential output growth assumption. The existence of both a large gap between real and potential output and a high rate of price rise at the beginning of 1971 strongly influences the response pattern of the endogenous variables over a short period.

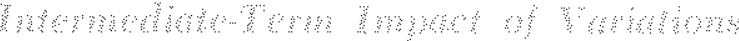

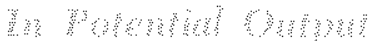

With some qualifications, the St. Louis model may be used to analyze the effect of variations in potential output on key economic indicators over some intermediate period. The period selected is the 1971-80 decade, a period long enough for trend factors to dominate the changes in potential output. The range of average growth of potential output over a decade should be less than for over the relatively short interval of two years. Given that potential output grew at about an average 3.8 per cent rate in both the 1950 's and 1960 's, and that it is expected to grow at a slightly faster rate in the $1970^{\circ} \mathrm{s}$, a 3.5 per cent to 4.5 per cent range should adequately capture the next ten-year average growth rate.

Changes in productivity resulting from variations in the rate of accumulation of capital, in technological progress, in educational advancement, in industry mix and in changing barriers to competitive markets, should be allowed for in this range of potential output growth. A severe change in the economic climate, such as occurred in the depression-dominated 1930's and 
the wartime 1940 s, could strongly infuence the growth of those factors determining potential output. For example, a sizable shift in the rate of capital accumulation could cause potential output to grow at some rate outside the postulated range of 3.5 to 4.5 per cent from 1971 to 1980 . The 3.5 to 4.5 per cent range should also permit normal variations in labor input to occur. The results obtained from the 1971-80 simulations employing the 3.5 to 4.5 per cent potential output range are given in the accompanying charts (the money supply is again assumed to grow at a 5 per cent rate; high-employment Federal expenditures are estimated to $I I / 1972$, and assumed to grow at an 8 per cent rate thereafter).

The ten-year simulations based on varying only the exogenous supply variable in the St. Louis model suggest that the composition of total spending (between prices and real output) depends strongly on the postulated rate of growth of potential output. The 3.5 to 4.5 per cent range is not wide, compared with the 2.5 to 5.5 per cent range employed in the short-run simulations, but it nevertheless provides an effective constraint on the performance of the economy over a decade. Because of the sizable degree of slack in the economy at the beginning of the simulation period, real output rises and the rate of inflation falls under slow or rapid potential output growth for several years. Eventually, the slack is eliminated and the slowing inflation-rising real output relation is reversed.

When potential output is assumed to grow at a 3.5 per cent rate, real output at the end of 1980 is rising at less than a 4 per cent rate while prices are increasing at a 1.7 per cent rate. In contrast, a 4.5 per cent

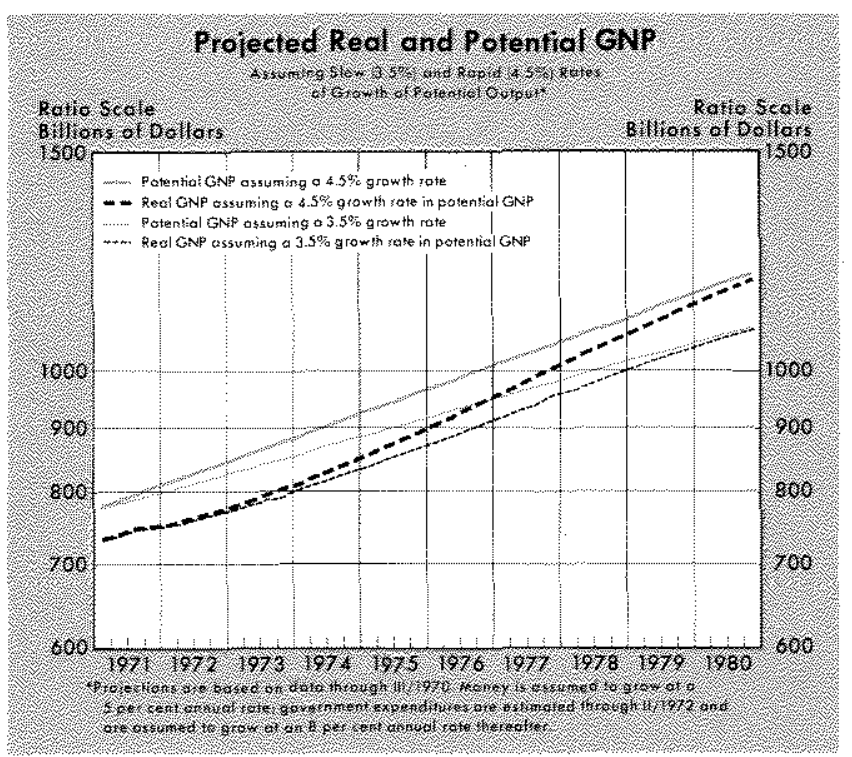

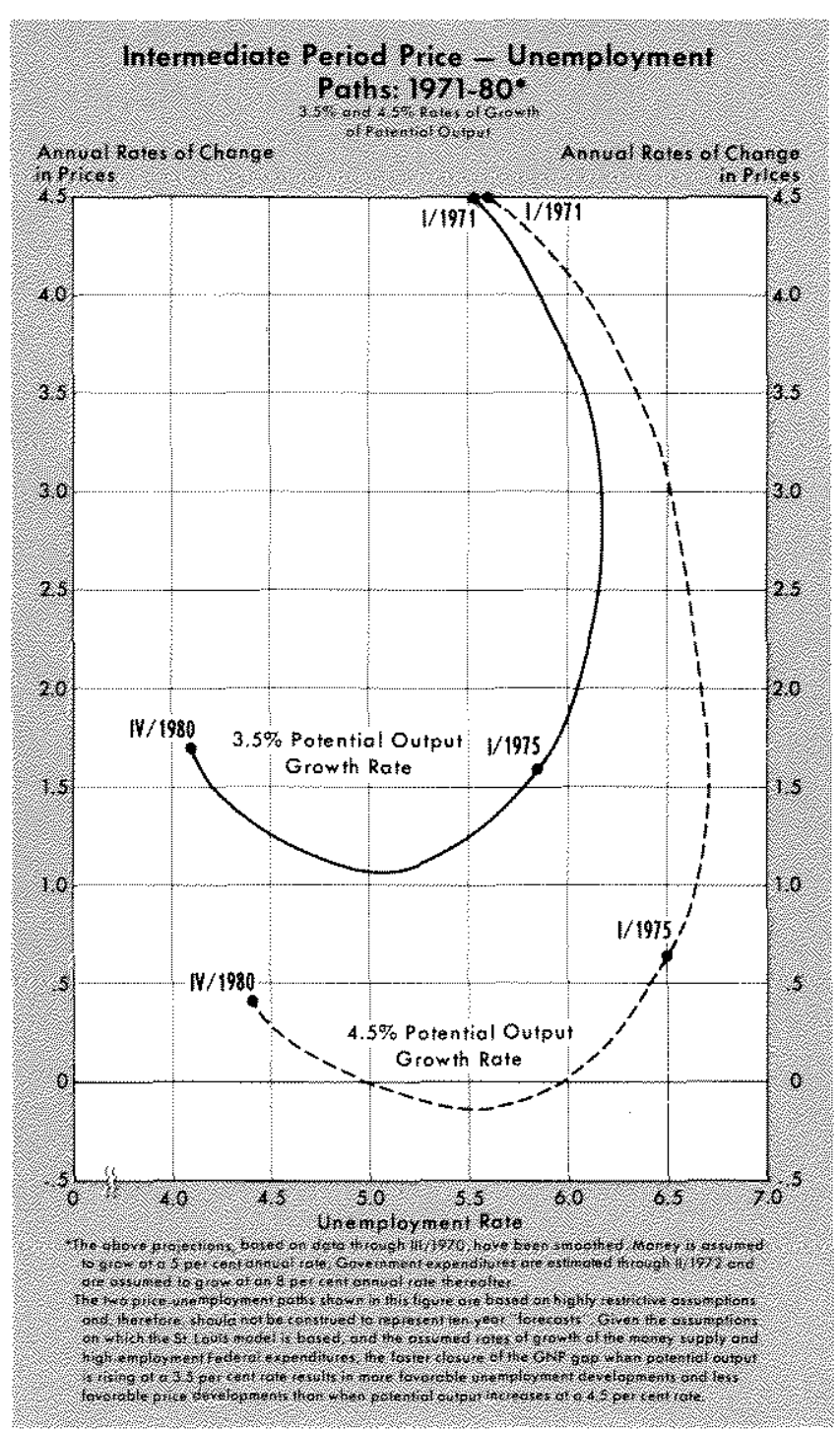

rate of growth of potential output throughout the 1970 's is accompanied by prices rising at the rate of only 0.4 per cent at the end of 1980 and real output increasing at a 5.3 per cent rate. The unemployment rate in late 1980 is somewhat higher when potential output grows at the faster 4.5 per cent rate, but only slightly above 4 per cent in either case. The differences in the price-unemployment paths over the next ten years (described by the above chart) arise because the gap between real and potential output is closed faster when potential output is increasing at the slower 3.5 per cent rate. ${ }^{14}$ The smaller the gap, that is, the closer the economy is to a full employment level of output, the more total spending is manifested in price increases and the less in real

14Note that the price-unemployment paths are traced only over an intermediate period, not a long-rum period over which the endogenous variables would be permitted to attain their equilibrium values. 
output. A smaller gap is also characterized, other things equal, by a lower unemployment rate. ${ }^{15}$

A faster rate of growth of potential output - the exogenous supply variable in the model-would be consistent with a faster rate of growth of the money supply - the chief exogenous demand variable. That is, if the supply of goods and services could be encouraged to grow at a relatively rapid rate, faster rising demand (stimulated by, say, a supply of money increasing at a rate which exceeds 5 per cent) would not foster either strong inflationary pressure or excessive unemployment over a ten-year period. Altematively, more rapid increases in the secular trend of income velocity than are implied by the model would foster more rapid rates of growth of total spending over the decade without increasing the money supply at more than a 5 per cent rate. This article has stressed possible changes in supply conditions, however, rather than demand factors which might lead to improved economic well-being over short- and intermediate-run periods.

\section{Summary}

Changes in productivity and labor input have important implications for the U.S. economy over shortand intermediate-run periods. Two principal determinants of the volume of labor inputs are labor force growth and work - leisure attitudes. The size of the labor force is determined by the death and net immigration rates, which have about stabilized in this

\footnotetext{
15The unemployment rate is determined directly in the St. Louis model by the gap between real and potential output. The function may be written in algebraic form as:

$\mathrm{U}_{t}=\mathrm{a}_{0}+\mathrm{b}_{1} \mathrm{G}_{t}+\mathrm{b}_{2} \mathrm{G}_{t-1}$, where $\mathrm{U}_{\mathrm{t}}=$ unemployment rate in the current quarter, $\mathrm{G}_{\mathrm{t}}=$ the gap in the current quarter, $\mathrm{G}_{t-1}=$ the gap in the previons quarter, and $\mathrm{a}_{0}, \mathrm{~b}_{ \pm}$and $\mathrm{b}_{2}$ are parameters. The gap is defined by $\mathrm{G}_{t}=\left[\left(\mathrm{X}_{\mathrm{t}}^{\mathrm{t}}-\mathrm{X}_{\mathrm{t}}\right)\right]$ $\left.X_{t}\right](100)$ where $X_{t}^{\prime}$ enrrent quarter potential output and $\mathrm{X}_{\mathrm{t}}=$ current quarter real output. See Leonall Andersen and Keith Carlson, "A Monetarist Model for Economic Stabilization, this Review (April 1970), pp. 9, 14.
}

country, the birth rate of at least 16 years earlier, and the labor force participation rate. A rising birth rate from 1955 to 1957 will expand the growth of the population of labor force age over the next few years, but a generally declining birth rate after 1957 will tend to slow the growth of this population in the second half of the 1970 's.

The size of the military establishment at a given time introduces an additional variable into the determination of the civilian labor force. The different age-sex groups of labor force age are buffeted by varied forces either encouraging or discouraging them from participating in the labor force, but, on balance, it appears that the overall participation rate will rise slightly over the next decade. Productivity, on the other hand, is expected by the Labor Department to rise at a slightly lower rate in the next decade than over the postwar period heretofore.

The short- and intermediate-run simulations employing the model of this Bank suggest that rapid increases in potential output are accompanied by relatively beneficial movements in prices and real output, but somewhat unfavorable changes in the unemployment rate. The unemployment rate could be lowered, however, despite rapid potential output advances, if total spending were stimulated sufficiently.

Potential output growth may be enhanced over short- or intermediate-term periods by increased labor and/or capital inputs and increased efficiency in their combination. Technological and educational advances, the lowering of entry barriers to individuals and firms, and more efficient utilization of labor and capital resources encourage potential output growth. The difficulty of implementing such measures would quite likely be outweighed by the resulting increases in the flow of goods and services. 